sucrose diluted in PBS containing 5\% BSA. When the solution appeared homogeneous, i was spun for $5 \mathrm{~min}$ at $500 \mathrm{~g}$. Supernatants $(30 \mu \mathrm{l})$ were inoculated i.c. into groups of four tga20 mice ${ }^{19}$. Infectivity titres were then determined using the relationship

$y=11.45-0.088 x\left(y, \log \mathrm{LD}_{50}\right.$ per millilitre of homogenate; $x$, incubation time in days to terminal disease), which was derived by linear regression using Prusiner's method ${ }^{17}$.

\section{Western blot analysis}

Tissue homogenates were adjusted to $5 \mathrm{mg} \mathrm{ml}^{-1}$ protein and run natively or after treatment with proteinase $\mathrm{K}\left(50 \mu \mathrm{g} \mathrm{ml}{ }^{-1}, 30 \mathrm{~min}, 37^{\circ} \mathrm{C}\right) .50 \mu \mathrm{g}$ of total protein were electrophoresed through 12\% SDS-PAGE and blotted. Membranes were incubated with monoclonal antibody ICSM18 to $\operatorname{PrP}(1: 20,000)^{27}$ or TH-2 to tyrosine hydroxylase (1:5,000; Sigma), and visualized by enhanced chemiluminescence (ECL; Amersham).

\section{Histology and immunohistochemistry}

Paraffin $(2 \mu \mathrm{m})$ and frozen sections from brain $(10 \mu \mathrm{m})$ or spleen $(5 \mu \mathrm{m})$ were stained with haematoxylin/eosin. Immunostaining for glial fibrillary acidic protein (GFAP) was performed with a rabbit antiserum (1:300 dilution; DAKO) and detected with biotinylated swine anti-rabbit serum (1:250 dilution; DAKO) and diaminobenzidine (Sigma). Antibodies FDC-M1 (clone 4C11; 1:50; Becton Dickinson), CD35 (8C12; Pharmingen) and anti-CD45RO/B220 (RA3-6B2; Pharmingen) were used as described ${ }^{28}$. For the assessment of splenic innervation, floating sections were blocked in $4 \%$ goat serum, incubated overnight with a polyclonal anti-TH antibody (1:400; Fluka), washed, and incubated with a biotinylated secondary antibody (1:100 goat anti rabbit; Vector). Visualization was accomplished with nickel-enhanced diaminobenzidine. Morphometric analysis was performed using Analysis Pro 3.1 software (Soft Imaging System; Münster). FDCs were quantified by measuring the FDC-M1 $1^{+}$surface in $\geq 48 \mathrm{WT}$ and CXCR5 ${ }^{-1}$ follicles. For LT $\beta$ R-Fc and human-IgG-treated mice, $\geq 12$ follicles were examined.

\section{Treatment with LT $\beta R$ fusion protein}

Mice were treated i.p. with $250 \mu \mathrm{g}$ LT $\beta$ R-Ig fusion protein ${ }^{29}$ one week before prion inoculation. Injection was repeated 14 and 28 days later. For control, Sv129 mice were subjected to the same regimen with $250 \mu \mathrm{g}$ of a human IgG polyclonal preparation (Biogen) instead of LT $\beta$ R-Ig. Two mice from each group were analysed for prion infectivity and $\mathrm{PrP}^{\mathrm{Sc}}$ content 38 days after inoculation.

\section{Bone marrow chimaeric mice}

$5 \times 10^{6}$ bone marrow cells were isolated from tibiae and femurs, and injected into tail veins of 8-10-week-old recipients conditioned by whole-body irradiation (1,100 rad) $24 \mathrm{~h}$ earlier. 6-8 weeks after grafting, reconstitution was assessed by FACS analysis of periphera blood taken from the retro-orbital plexus of ether-anaesthetized mice. Blood samples were prepared at $4{ }^{\circ} \mathrm{C}$ in buffer solution (PBS containing $2 \% \mathrm{FCS}$ and $0.2 \% \mathrm{NaN}_{3}$ ) and stained with fluorescein isothiocyanate (FITC)-labelled CD45R/B220 (Pharmingen) and phycoerythrin (PE)-labelled anti-CXCR5 (clone 2G8; ref. 13). After lysis of erythrocytes with FACS lysis solution (Becton Dickinson) and washing, cell suspensions were analysed with a FACSCalibur (Becton Dickinson). Viable cells were gated by forward and side light scatter. Data were acquired with CellQuest software (Becton Dickinson). The following markers were used: anti-B220-PerCP, anti-CD21-FITC, anti-CD23-bio, anti-CD23-PE, anti-CD18-PE, anti-CD29-biotin, anti-CD49d-biotin, anti-CD5-bio, anti-CD11b (Mac-1)-FITC, anti-CD11a-biotin and streptavidin-APC (all from BD-Pharmingen). For characterization of marginal zone-B (MZB) and follicular B (FB) cells, a combination of anti-B220/CD21/CD23 was used. For detection of integrin expression on MZB cells, antiCD49d (anti- $\alpha 4$ ), anti-CD11a (anti- $\alpha$ L $\beta 2$ ), anti-CD18 (anti- $\beta 2$ ) and anti-CD29 (anti- $\beta 1$ ) antibodies were combined with the anti-B220/CD21/CD23 stain. For identification of peritoneal B-1 and B-2 cells, a combination of anti-B220/CD5/CD11b antibodies was used.

Received 22 August; accepted 25 September 2003; doi:10.1038/nature02072. Published online 15 October 2003.

1. Aguzzi, A., Montrasio, F. \& Kaeser, P. S. Prions: health scare and biological challenge. Nature Rev. Mol. Cell Biol. 2, 118-126 (2001).

2. Aguzzi, A. Neuro-immune connection in spread of prions in the body? Lancet 349, 742-743 (1997)

3. Klein, M. A. et al. A crucial role for B cells in neuroinvasive scrapie. Nature 390, 687-690 (1997)

4. Race, R., Oldstone, M. \& Chesebro, B. Entry versus blockade of brain infection following oral or intraperitoneal scrapie administration: role of prion protein expression in peripheral nerves and spleen. J. Virol. 74, 828-833 (2000).

5. Eklund, C. M., Kennedy, R. C. \& Hadlow, W. J. Pathogenesis of scrapie virus infection in the mouse J. Infect. Dis. 117, 15-22 (1967).

6. Kimberlin, R. H. \& Walker, C. A. The role of the spleen in the neuroinvasion of scrapie in mice. Virus Res. 12, 201-211 (1989).

7. Prinz, M. et al. Lymph nodal prion replication and neuroinvasion in mice devoid of follicular dendritic cells. Proc. Natl Acad. Sci. USA 99, 919-924 (2002).

8. Klein, M. A. et al. PrP expression in B lymphocytes is not required for prion neuroinvasion. Nature Med. 4, 1429-1433 (1998).

9. Montrasio, F. et al. Impaired prion replication in spleens of mice lacking functional follicular dendritic cells. Science 288, 1257-1259 (2000).

10. Kitamoto, T., Muramoto, T., Mohri, S., Doh-ura, K. \& Tateishi, J. Abnormal isoform of prion protein accumulates in follicular dendritic cells in mice with Creutzfeldt-Jakob disease. J. Virol. 65, 6292-6295 (1991).

11. Glatzel, M., Heppner, F. L., Albers, K. M. \& Aguzzi, A. Sympathetic innervation of lymphoreticular organs is rate limiting for prion neuroinvasion. Neuron 31, 25-34 (2001).

12. Heinen, E., Bosseloir, A. \& Bouzahzah, F. Follicular dendritic cells: origin and function. Curr. Top. Microbiol. Immunol. 201, 15-47 (1995).

13. Forster, R. et al. A putative chemokine receptor, BLR1, directs B cell migration to defined lymphoid organs and specific anatomic compartments of the spleen. Cell 87, 1037-1047 (1996).

14. Voigt, I. et al. CXCR5-deficient mice develop functional germinal centers in the splenic $\mathrm{T}$ cell zone. Eur. J. Immunol. 30, 560-567 (2000).

15. Felten, D. L. \& Felten, S. Y. Sympathetic noradrenergic innervation of immune organs. Brain Behav Immun. 2, 293-300 (1988)

16. Carlson, S. L. et al. NGF modulates sympathetic innervation of lymphoid tissues. J. Neurosci. 15, 5892-5899 (1995).

17. Prusiner, S. B., Cochran, S. P., Downey, D. E. \& Groth, D. F. Determination of scrapie agent titer from incubation period measurements in hamsters. Adv. Exp. Med. Biol. 134, 385-399 (1981).

18. Kaeser, P. S., Klein, M. A., Schwarz, P. \& Aguzzi, A. Efficient lymphoreticular prion propagation requires prp(c) in stromal and hematopoietic cells. J. Virol. 75, 7097-7106 (2001).

19. Fischer, M. et al. Prion protein ( $\mathrm{PrP})$ with amino-proximal deletions restoring susceptibility of $\operatorname{PrP}$ knockout mice to scrapie. EMBO J. 15, 1255-1264 (1996).

20. Beekes, M., Baldauf, E. \& Diringer, H. Sequential appearance and accumulation of pathognomonic markers in the central nervous system of hamsters orally infected with scrapie. J. Gen. Virol. 77, 1925-1934 (1996).

21. Oldstone, M. B. et al. Lymphotoxin- $\alpha$ - and lymphotoxin- $\beta$-deficient mice differ in susceptibility to scrapie: evidence against dendritic cell involvement in neuroinvasion. J. Virol. 76, 4357-4363 (2002).

22. Mackay, F. \& Browning, J. L. Turning off follicular dendritic cells. Nature 395, $26-27$ (1998)

23. Ansel, K. M. et al. A chemokine-driven positive feedback loop organizes lymphoid follicles. Nature 406, 309-314 (2000).

24. Hill, A. F., Zeidler, M., Ironside, J. \& Collinge, J. Diagnosis of new variant Creutzfeldt-Jakob disease by tonsil biopsy. Lancet 349, 99-100 (1997).

25. Hilton, D. A., Fathers, E., Edwards, P., Ironside, J. W. \& Zajicek, J. Prion immunoreactivity in appendix before clinical onset of variant Creutzfeldt-Jakob disease. Lancet 352, 703-704 (1998).

26. Aguzzi, A., Glatzel, M., Montrasio, F., Prinz, M. \& Heppner, F. L. Interventional strategies against prion diseases. Nature Rev. Neurosci. 2, 745-749 (2001)

27. Hill, A. F. et al. Species-barrier-independent prion replication in apparently resistant species. Proc Natl Acad. Sci. USA 29, 10248-10253 (2000).

28. Karrer, U. et al. Antiviral B cell memory in the absence of mature follicular dendritic cell networks and classical germinal centers in TNFR1-/- mice. J. Immunol. 164, 768-778 (2000).

29. Wu, Q. et al. Reversal of spontaneous autoimmune insulitis in nonobese diabetic mice by soluble lymphotoxin receptor. J. Exp. Med. 193, 1327-1332 (2001).

Acknowledgements We thank C. Sigurdson and M. Zabel for critical reading of the manuscript, and R. Zinkernagel for support. This work was supported by grants of the Bundesamt für Bildung und Wissenschaft, the Swiss National Foundation, the NCCR on neural plasticity and repair, and the Migros foundation to A.A. M.P. was a postdoctoral fellow of the Deutsche Forschungsgemeinschaft. M.H. is supported by a generous educational grant of the Catello family and by the Verein zur Förderung des Akademischen Nachwuchses. F.L.H. is supported by the Stammbach Foundation and by the Bonizzi-Theler Foundation.

Competing interests statement The authors declare that they have no competing financial interests.

Correspondence and requests for materials should be addressed to A.A. (adriano@pathol.unizh.ch).

Bmi-1 dependence distinguishes neural stem cell self-renewal from progenitor proliferation

\section{Anna V. Molofsky ${ }^{\star}$, Ricardo Pardal ${ }^{\star}$, Toshihide Iwashita, In-Kyung Park, Michael F. Clarke \& Sean J. Morrison}

Howard Hughes Medical Institute, and Departments of Internal Medicine and Cell and Developmental Biology, University of Michigan, Ann Arbor, Michigan 48109-0934, USA

* These authors contributed equally to this work

Stem cells persist throughout life by self-renewing in numerous tissues including the central ${ }^{1}$ and peripheral ${ }^{2}$ nervous systems. This raises the issue of whether there is a conserved mechanism to effect self-renewing divisions. Deficiency in the polycomb family transcriptional repressor $\mathrm{Bmi}-1$ leads to progressive postnatal growth retardation and neurological defects ${ }^{3}$. Here we show that $B m i-1$ is required for the self-renewal of stem cells in the peripheral and central nervous systems but not for their survival or differentiation. The reduced self-renewal of Bmi-1-deficient neural stem cells leads to their postnatal depletion. In the absence of Bmi-1, the cyclin-dependent kinase inhibitor gene $p 16^{I n k 4 a}$ is 
upregulated in neural stem cells, reducing the rate of proliferation. $p 16^{\text {Ink4a }}$ deficiency partially reverses the self-renewal defect in Bmi-1 $1^{-1-}$ neural stem cells. This conserved requirement for $B m i-1$ to promote self-renewal and to repress $p 16^{I n k 4 a}$ expression suggests that a common mechanism regulates the self-renewal and postnatal persistence of diverse types of stem cell. Restricted neural progenitors from the gut and forebrain proliferate normally in the absence of Bmi-1. Thus, Bmi-1 dependence distinguishes stem cell self-renewal from restricted progenitor proliferation in these tissues.

$B m i-1$ is an oncogene that causes neoplastic proliferation when overexpressed in lymphocytes ${ }^{4,5}$. Deletion of Bmi-1 leads to defects in axial skeleton patterning and haematopoiesis, and to ataxia and seizures ${ }^{3}$. Bmi-1-deficient mice can survive into adulthood but show progressive postnatal growth retardation (ref. 3 and Supplementary Fig. 1), raising the possibility that Bmi-1 regulates stem cell function. Two studies have shown that Bmi-1 is required for the postnatal maintenance of haematopoietic stem cells $s^{6,7}$. In those studies, however, it was not technically possible in the haematopoietic system to discern directly whether the failure of stem cell maintenance was caused by a defect in self-renewal or survival.

To determine whether Bmi-1 regulates the self-renewal of mouse neural stem cells, we examined the effect of Bmi-1 deficiency on the self-renewal of central nervous system (CNS) stem cells from the telencephalon at embryonic day $14.5(\mathrm{E} 14.5)^{8}$ and neural crest stem cells (NCSCs) from the gut at E14.5 (enteric nervous system) ${ }^{9}$. CNS stem cells form CNS neurospheres, whereas gut NCSCs form PNS neurospheres in non-adherent cultures (Fig. 1 and Supplementary Fig. 3). CNS and PNS neurospheres and purified uncultured p $75^{+} \alpha_{4}^{+}$rat gut $\mathrm{NCSCs}^{9}$ expressed Bmi-1 (Supplementary Fig. 2 and data not shown). Bmi-1 $1^{-1-}$ telencephalon cells formed multipotent neurospheres, but at a significantly lower frequency $(P<0.05)$ than did wild-type telencephalon cells (Fig. 1). This suggests that there are significantly fewer stem cells in the Bmi-1 ${ }^{-1-}$ telencephalon. The $B m i-1^{-l-}$ neurospheres were also roughly 14 -fold smaller in volume $(P<0.01)$ and gave rise to 33 -fold fewer $(P<0.01)$ secondary neurospheres on subcloning, indicating a defect in self-renewal. In the E14.5 PNS, the frequency of cells capable of forming neurospheres did not differ between wild-type and $B m i-1^{-1-}$ guts, but the $B m i-1^{-/-}$neurospheres were significantly smaller and gave rise to 60 -fold fewer secondary multipotent neurospheres $(P<0.01)$ on subcloning (Fig. 1). Thus, Bmi-1 deficiency reduced the self-renewal of both CNS stem cells and NCSCs in culture.

If neural stem cells require Bmi-1 for normal self-renewal in vivo, the stem cells in Bmi-1-deficient mice should become depleted postnatally. In the absence of Bmi-1, the frequency of lateral

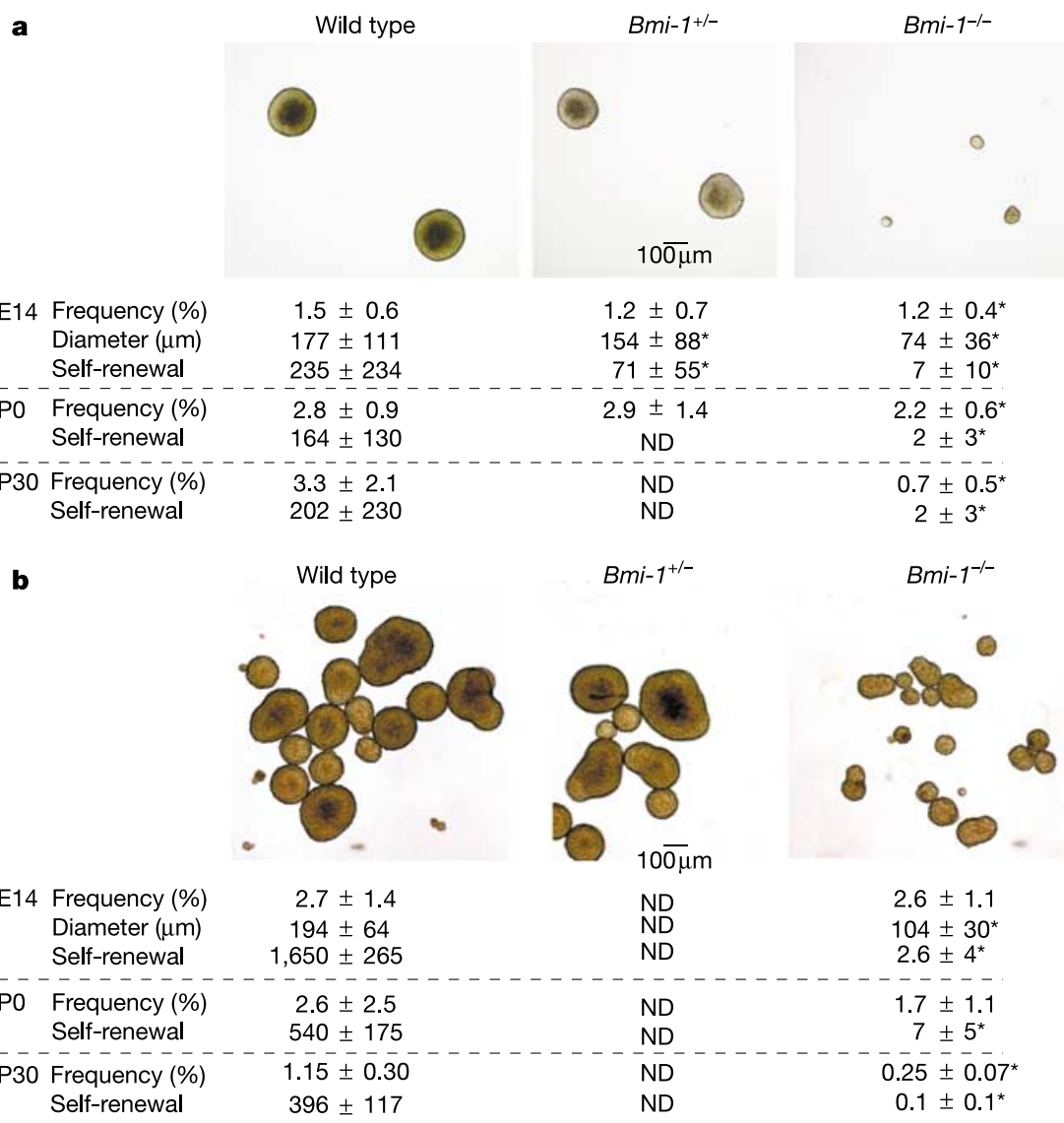

Figure 1 CNS stem cells and gut neural crest stem cells (NCSCs) require Bmi-1 to selfrenew normally. Images show typical neurospheres that formed after $10 \mathrm{~d}$ in nonadherent cultures from E14.5 CNS neural stem cells (a) or PNS NCSCs (b). a, The frequency of $B \mathrm{mi}^{-1} \mathrm{1}^{-1-}$ E14 telencephalon cells, PO SVZ cells or P30 SVZ cells that formed multipotent CNS neurospheres was significantly reduced relative to wild-type cells $\left({ }^{\star} P<0.05\right)$. The diameter and self-renewal of the $B m i-1^{-1-}$ neurospheres were also significantly reduced. Self-renewal capacity is expressed as the number of secondary neurospheres generated per primary neurosphere on subcloning. $\mathbf{b}$. Similar results were obtained for multipotent PNS neurospheres generated by E14.5, P0 or P30 wild-type and $B \mathrm{mi}^{-1^{-1-}}$ gut cells, except that the frequency of neurosphere-forming cells was not significantly reduced until P30. Values are the mean \pm s.d. for 3-6 independent experiments. Bmi- 1 deficiency also consistently reduced self-renewal when the data were normalized to control for differences in the size of neurospheres: $3.5 \pm 0.8 \%$ of dissociated wild-type PO PNS neurosphere cells formed secondary neurospheres on subcloning, as compared with $0.3 \pm 0.1 \%$ of $B m i-1^{-1-}$ cells $(P<0.001)$. ND, not determined. 
ventricle subventricular zone (SVZ) cells and gut cells that were capable of forming multipotent neurospheres in culture was modestly reduced at postnatal day $0(\mathrm{P} 0)$ and strongly reduced at P30 (Fig. 1). Similar trends were observed in terms of the ability of the cells to form multilineage adherent colonies in culture (data not shown). The extent to which Bmi-1 deficiency reduced the selfrenewal potential of stem cells increased over time (Fig. 1). Thus, $B m i-1$ is required for the self-renewal of stem cells in diverse tissues, and $B m i-1^{-1-}$ stem cells rarely persist into adulthood.

Consistent with the reduction in neurosphere size (Fig. 1), $B m i-1^{-1-}$ neural stem cell colonies contained one-third to onetenth as many cells as did wild-type colonies (Fig. 2a). We were unable to detect any increase in cell death in $B m i-1^{-1-}$ stem cell colonies or in the SVZ of the lateral ventricle in vivo (Fig. 2b-d). By contrast, the proliferation of cells in stem cell colonies was significantly reduced (Fig. 2e, f). Thus, the reduced self-renewal of $B m i-1^{-1-}$ neural stem cells was caused at least partly by reduced proliferation.

To assess the effect of Bmi-1 on proliferation in vivo, we examined the rate of 5-bromodeoxyuridine (BrdU) incorporation into $\mathrm{P} 0$ and P30 SVZ cells. As compared with wild-type SVZ cells, Bmi-1 ${ }^{-/-}$ SVZ cells showed a significantly lower rate of BrdU incorporation at both ages $\left(17.8 \pm 0.5 \%\left(B m i-1^{-l-}\right)\right.$ versus $19.9 \pm 2.0 \%$ (wild type) of SVZ cells were BrdU-positive at P0; $P<0.05$ ), although the effect was greater at P30 $(13.1 \pm 2.7 \%$ versus $20.1 \pm 0.5 \%$; $P<0.01$ ).

$B m i-1$ deficiency is associated with increased expression of the

a

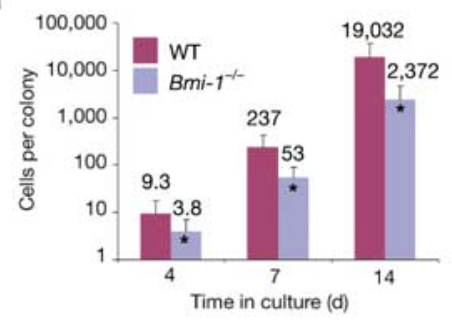

b
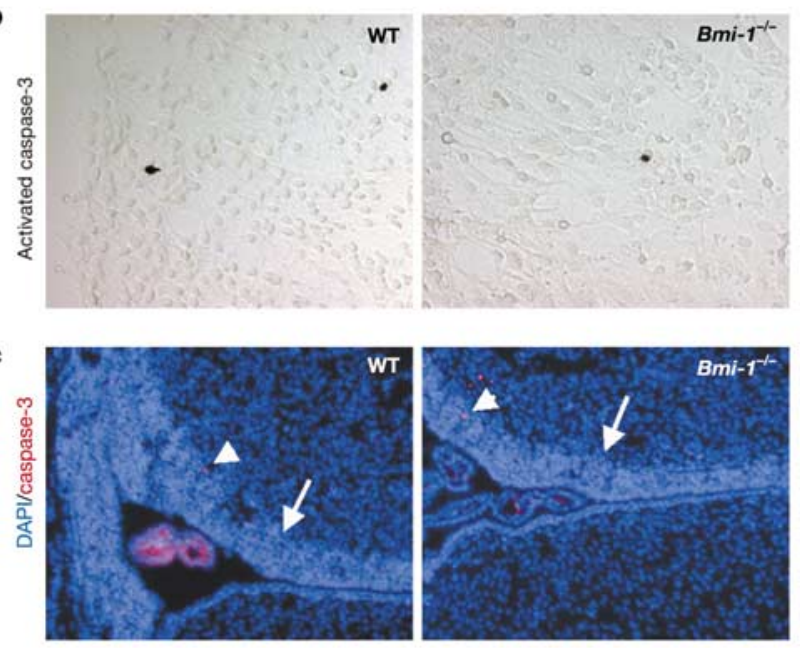

Figure 2 Bmi-1 deficiency reduces proliferation but does not increase cell death in CNS stem cell colonies. PO SVZ cells were dissociated and plated in adherent cultures, and the number of cells per colony was counted after 4, 7 and $14 \mathrm{~d}$ (a). All colonies were counted after $4 \mathrm{~d}$, but only colonies that contained neurons and glia were counted after 7 and $14 \mathrm{~d}$. At all time points, wild-type (WT) colonies contained significantly more cells than the Bmi-1 ${ }^{-1-}$ colonies ( ${ }^{*} P<0.01$ ). Similar results were obtained at E14 and P30 (not shown). Only a few cells in adherent CNS stem cell colonies (b) or in the PO SVZ (c) stained with antibodies against activated caspase-3 (a marker of cell death). Arrows and arrowheads indicate the SVZ and caspase-3-positive cells, respectively. Note that the $p 16^{\text {Ink4a }}$ and $p 19^{A r f}$ genes encoding cyclin-dependent kinase inhibitors, and deletion of these genes partially rescues the growth of $B m i-1^{-1-}$ mice ${ }^{10-12}$. Analysis by quantitative real-time polymerase chain reaction (qRT-PCR) showed that $p 16^{\operatorname{Ink} 4 a}$ expression increased 5-21-fold, whereas $p 19^{\text {Arf }}$ expression increased 1.4-3fold, in Bmi-1 ${ }^{-1-}$ CNS and PNS neurospheres of all ages (Supplementary Table 1 and Supplementary Figs $4 \mathrm{f}$ and 5f). To test whether $p 16^{\text {Ink } 4 a}$ regulates neural stem cell self-renewal, we examined neurospheres cultured from $p 16^{-1-}$ adult mice (ref. 13 and Fig. 3). $p 16^{-1-}$ neurospheres from both the CNS and PNS were larger and self-renewed to a significantly greater extent than did wild-type neurospheres (Fig. 3a, b). Adherent CNS and PNS p16 ${ }^{-1-}$ stem cell colonies contained more cells and incorporated BrdU at a higher rate (Fig. $3 c-f)$. These data indicate that $p 16^{\text {Ink4a }}$ inhibits neural stem cell self-renewal in culture, although the magnitude of this effect may depend on culture conditions, because $p 16^{\operatorname{Ink} 4 a}$ can be induced in response to stress ${ }^{14}$.

To address directly whether Bmi-1 promotes neural stem cell selfrenewal by suppressing the expression of $p 16^{\operatorname{Ink} 4 a}$, we generated Bmi-1 $1^{-1-}$ p $16^{-1-}$ mice. p16 ${ }^{\text {Ink4a }}$ deficiency significantly increased the self-renewal of $B m i-1^{-1-}$ CNS stem cells and NCSCs in culture $(P<0.01)$, but did not fully restore self-renewal to wild-type levels (Fig. 3g, h). This indicates that there are additional pathways downstream of Bmi-1 that regulate self-renewal, perhaps including $p 19^{A r f}$. The increased self-renewal of Bmi-1 $1^{-1-}$ p $16^{-1-}$ CNS stem cells and NCSCs was associated with a significant increase in the rate of proliferation in stem cell colonies $(23.5 \pm 11.1 \%$ BrdU-

d

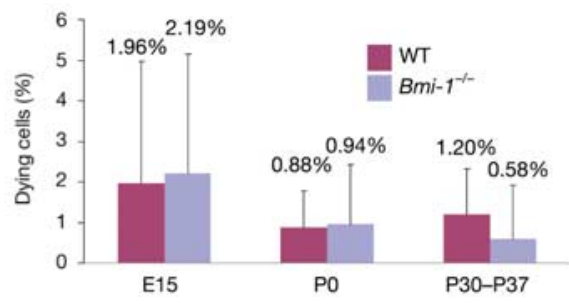

e

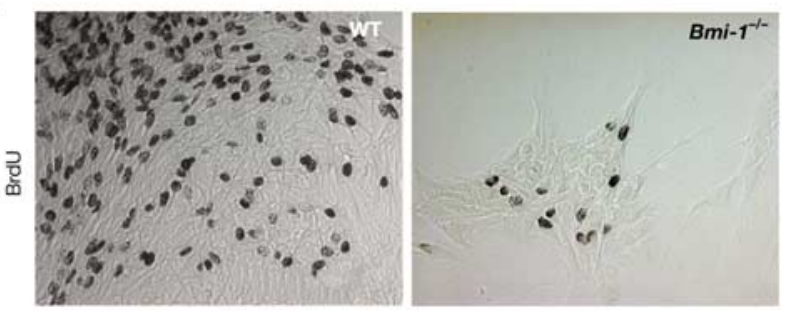

$\mathbf{f}$

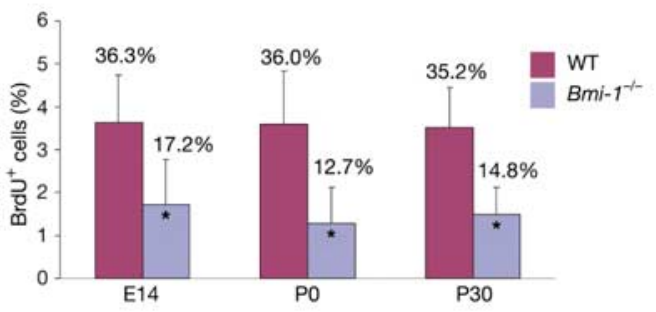

choroid plexus in the lateral ventricle is highly autofluorescent (c). No statistically significant difference in the frequency of dying cells was observed between wild-type and $B m i-1^{-1-}$ CNS stem cell colonies on the basis of the frequency of condensed, fragmented nuclei identified by 4 ',6-diamidino-2-phenylindole dihydrochloride (DAPI) staining (d), or activated caspase-3 (not shown). Bmi-1 deficiency was associated with a significant decrease in the rate of BrdU incorporation into CNS stem cell colonies

$\left(\mathbf{e}, \mathbf{f} ;{ }^{*} P<0.01\right)$, indicating reduced proliferation. A similar reduction in proliferation was observed in Bmi-1 ${ }^{-1-}$ NCSC colonies in culture (not shown). 
positive cells versus $8.9 \pm 11.6 \%$ in $B m i-1^{-I-} p 16^{+/+}$CNS stemcell colonies, $P<0.01)$. Therefore, the increase in $p 16^{\text {Ink4a }}$ expression in the absence of Bmi-1 contributed to the reduced self-renewal of $B m i-1^{-/-}$neural stem cells in culture.

Because $p 16^{\text {Ink } 4 a}$ and $p 19^{\text {Arf }}$ expression can increase in cultured cells ${ }^{15}$, we examined whether these genes were also upregulated in uncultured progenitors (Supplementary Table 1). Expression of p16 ${ }^{\text {Ink4a }}$ RNA and protein was increased in the P0 and P30 SVZ of Bmi-1 $1^{-1-}$ mice but was not detected in the E15 telencephalon (Supplementary Table 1 and Supplementary Fig. 4e). p16 $6^{\text {Ink4a }}$ was also upregulated in uncultured $B m i-1^{-l-}$ P30 SVZ FSC ${ }^{\text {hi }}$ SEA $-1^{\text {hi }} \mathrm{CD} 24^{-/ \mathrm{lo}}$ cells, which are enriched for CNS stem cells ${ }^{16,17}$. Expression of $p 19^{A r f}$ followed similar trends but was upregulated to a lesser extent than $p 16^{\text {Ink4a }}$ (Supplementary Table 1). In the PNS, p16 ${ }^{\text {Ink } 4 a}$ and $p 19^{\text {Arf }}$ followed trends similar to those observed in the CNS. Expression of $p 16^{\text {Ink4a }}$ was also increased in P0 and P30 uncultured $B m i-1^{-I-}$ p $75^{+}$gut cells, which are enriched for

a
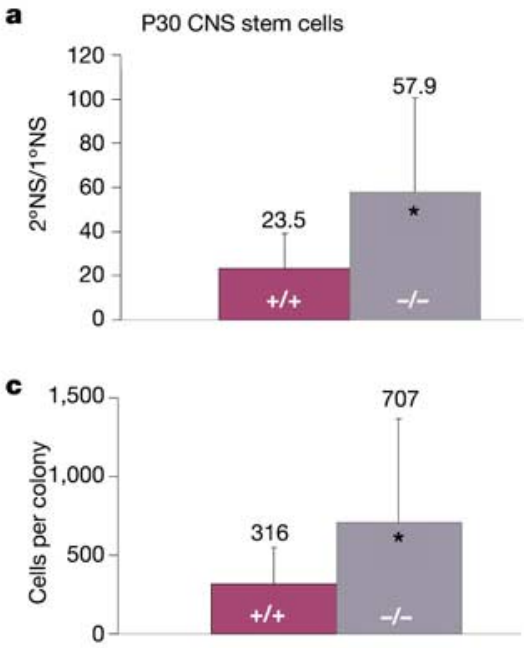

e

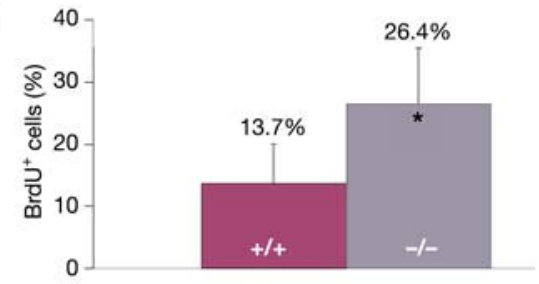

g

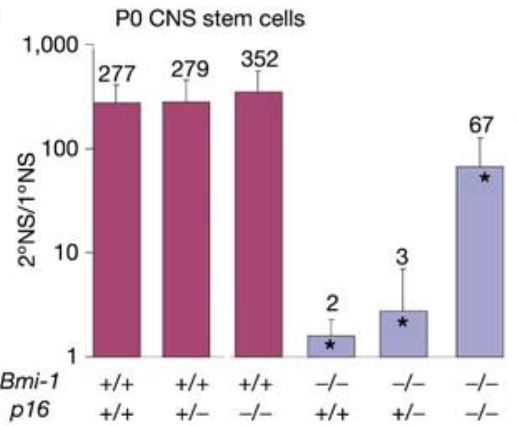

NCSCs ${ }^{2}$. Consistent with the increased expression of $p 16^{\text {Ink } 4 a}$ in the nervous system of Bmi-1-deficient mice in vivo, p16 deficiency partially rescued at least some aspects of nervous system development in Bmi-1 $1^{-1-}$ mice. For example, the number of neurons per section through the P30 distal small intestine was $92 \pm 30$ (mean \pm s.d.) for wild-type, $47 \pm 19$ for $B m i-1^{-l-}$ and $78 \pm 18$ for $B m i-1^{-l-}$ $p 16^{-1-}$ mice (all differences $P<0.05$ ).

These data suggest that $B m i-1$ is required in the nervous system in vivo to repress $p 16^{\text {Ink4a }}$ and $p 19^{\text {Arf }}$ postnatally but not during fetal development. The lack of $p 16^{\text {Ink } 4 a}$ or $p 19^{A r f}$ expression in the $B m i-1^{-1-}$ telencephalon may be a reason why forebrain development seems relatively normal in $B m i-1^{-1-}$ newborns despite the poor proliferation of E14.5 $\mathrm{Bmi-1} \mathrm{1}^{-1-}$ neurospheres, which do express $p 16^{\text {Ink } 4 a}$ in culture. Nonetheless, $p 16^{\text {Ink } 4 a}$ expression was increased in vivo in the Bmi-1 ${ }^{-1-} \mathrm{SVZ}$ at $\mathrm{P} 0$ and $\mathrm{P} 30$, consistent with the proliferation defect observed in the postnatal SVZ and with the postnatal depletion of stem cells.

b P30 NCSCs
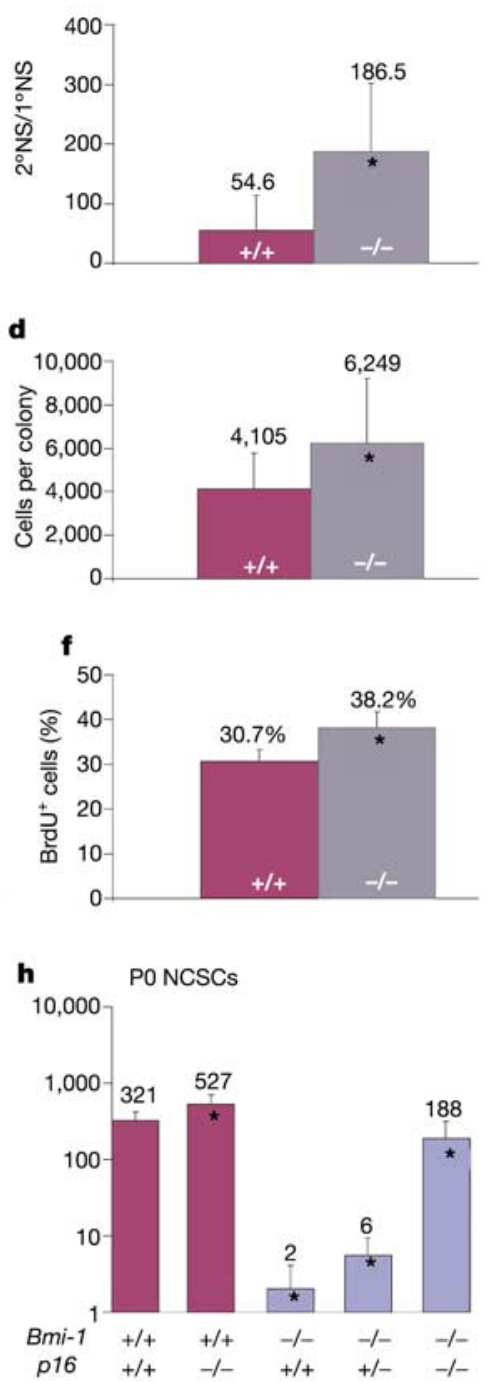

Figure $3 p 16^{\text {Ink4a }}$ negatively regulates the self-renewal of CNS stem cells and gut NCSCs in culture. SVZ and gut cells from adult $p 16^{-/-}$and wild-type mice were dissociated and cultured to generate neurospheres $(\mathbf{a}, \mathbf{b})$ or adherent stem cell colonies $(\mathbf{c}-\mathbf{f})$. After $7 \mathrm{~d}$ $(\mathbf{a}, \mathbf{c}, \mathbf{e})$ or $10 \mathrm{~d}(\mathbf{b}, \mathbf{d}, \mathbf{f})$ in culture, self-renewal $(\mathbf{a}, \mathbf{b})$, the total number of cells per colony $(\mathbf{c}, \mathbf{d})$, and the percentage of BrdU-positive cells per colony $(\mathbf{e}, \mathbf{f})$ were assayed. In each case, the $p 16^{-/-}$adult neural stem cell colonies self-renewed more, proliferated more and contained more cells $\left({ }^{\star} P<0.05\right)$. No differences were observed between $p 16^{-1-}$ and wild-type colonies in the frequency of apoptotic cells $(0.59 \pm 0.61 \%$ versus $0.35 \pm 0.48 \%$ respectively). Bmi- $1^{+/-} \mathrm{p} 16^{+/-}$mice were also bred to generate P0 pups, from which SVZ CNS stem cells $(\mathbf{g})$ and gut NCSCs $(\mathbf{h})$ were cultured. For both types of cell, $p 16^{\operatorname{lnk} 4 a}$ deficiency significantly increased the self-renewal of $B m i-1^{-1-}$ stem cells $\left({ }^{*} P<0.01\right)$, although it did not fully restore self-renewal to wild-type levels $\left({ }^{\star} P<0.01\right.$ relative to wild type). Note that $p 16^{\operatorname{lnk} 4 a}$ deficiency in $B m i-1^{+/+}$stem cells significantly increased the self-renewal of PO NCSCs (h) but not PO CNS stem cells $(\mathbf{g})$. 
The proliferation of restricted neural progenitors might be regulated differently from that of stem cells because restricted progenitors are not multipotent and divide a limited number of times before becoming postmitotic. To test whether these cells are dependent on Bmi-1, we cultured E14 telencephalon cells, or P0 or P30 SVZ cells, at clonal density under adherent conditions. In contrast to the significantly reduced frequency of stem cells in Bmi-1 $1^{-l-}$ samples (Fig. 1), the frequency of cells that formed neuron-only or glia-only colonies did not significantly differ between wild-type and Bmi-1 $1^{-1-}$ samples (Fig. 4a). There were also no significant differences in the number of cells per neurononly or glia-only colony from the CNS or PNS (Fig 4b-e). Thus, $B m i-1^{-l-}$ restricted neural progenitors were present in relatively normal numbers and proliferated normally in culture.

To test whether lineage commitment caused the proliferation of neural progenitors to become Bmi-1 independent, we cultured E14 gut $\mathrm{p} 75^{+}$neural crest cells at clonal density for $4 \mathrm{~d}$ with or without bone morphogenetic protein 4 (BMP4), which instructs gut NCSCs to undergo neurogenesis ${ }^{9,18,19}$. In the absence of BMP4 no neurononly colonies were observed in these cultures, but in the presence of BMP4 significant numbers of neuron-only colonies emerged. The number of cells per neuron-only colony did not differ between wildtype and Bmi-1 $1^{-1-}$ cultures (Fig. $4 \mathrm{e}$ ).

Neuregulin $(\mathrm{Nrg})$ promotes the proliferation of glial progenitors in addition to instructing postnatal gut NCSCs to acquire a glial fate $e^{2,19,20}$. To test whether $B m i-1^{-1-}$ glial progenitors proliferated normally when stimulated by $\mathrm{Nrg}$, we cultured dissociated P0 gut cells in adherent cultures at clonal density with or without Nrg for $6 \mathrm{~d}$. In the absence of $\mathrm{Nrg}, \mathrm{Bmi-1} \mathrm{1}^{-1-}$ colonies incorporated BrdU (pulsed on day 6) at only a third of the rate of wild-type colonies; however, in the presence of $\mathrm{Nrg}, \mathrm{Bmi}-\mathrm{1}^{-1-}$ colonies incorporated $\mathrm{BrdU}$ at almost the same rate as wild-type colonies (Fig. 4f). These data indicate that lineage determination factors change the cellcycle regulation of stem cells in addition to restricting their developmental potential, causing the proliferation of neural progenitors to become Bmi-1 independent.

$B m i-1$ was expressed in restricted neural progenitors and $p 16^{\text {Ink } 4 a}$ RNA and protein expression remained increased in Bmi-1 ${ }^{-1-}$ restricted neural progenitor colonies (Supplementary Fig. 5f); however, $p 16^{\text {Ink } 4 a}$ deficiency did not affect the frequency or proliferation of restricted neural progenitors (Supplementary Fig. 5). Thus, lineage restriction was associated with a change in cell-cycle regulation that caused restricted neural progenitors to proliferate in culture in a way that was not affected by Bmi-1 or $p 16^{\text {Ink4a }}$ deficiency.

The reduced stem cell frequency in the $B m i-1^{-1-}$ telencephalon (Fig. 1) indicates that other pathways downstream of Bmi-1 may also regulate self-renewal, because neither $p 16^{\text {Ink4a }}$ nor $p 19^{A r f}$ was a

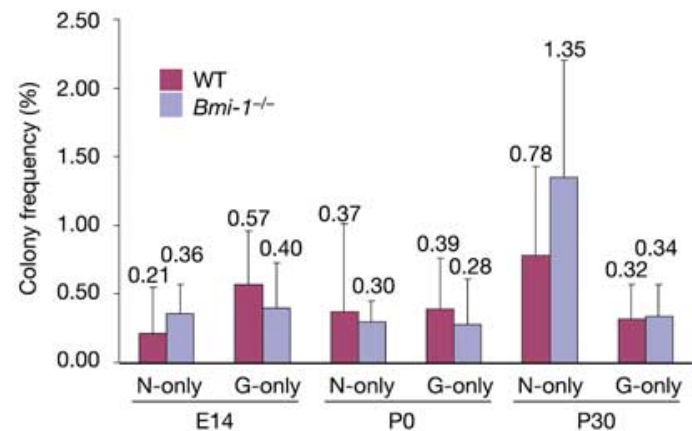

c

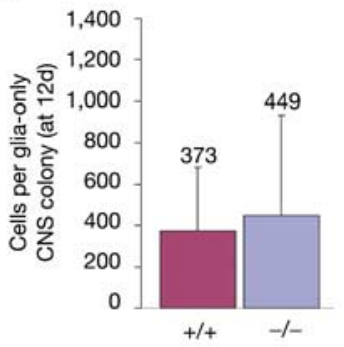

d

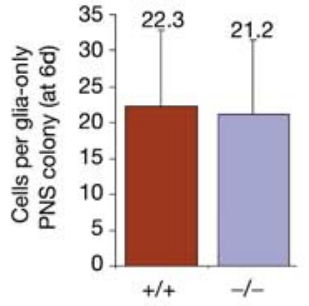

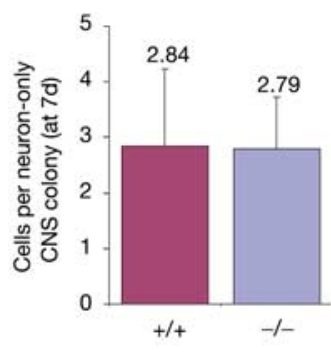

e

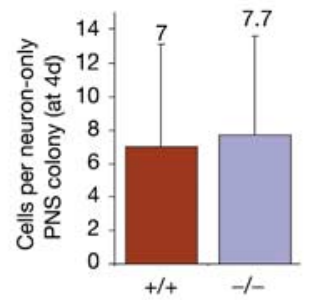

$\mathbf{f}$

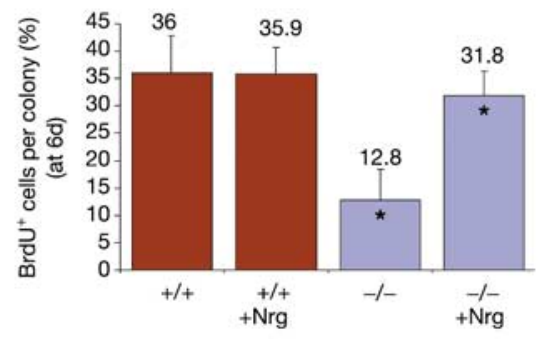

Figure 4 Restricted neural progenitors from the CNS and PNS proliferate normally in the absence of Bmi-1. E14 telencephalon cells or P0 or P30 SVZ cells were dissociated and cultured at clonal density under adherent conditions. a-c, The frequency of CNS cells that formed neuron-only or glia-only colonies after $12-14 \mathrm{~d}$ in culture did not significantly differ between wild-type (WT) and Bmi-1 ${ }^{-1-}$ mice (a), nor did the number of cells per neuron-only colony (b) or glia-only colony (c). d, The number of cells per glia-only colony formed by dissociated PO gut cells did not differ between wild-type and $\mathrm{Bmi-1^{-/- }}$ mice. e, In BMP4-treated cultures of E14.5 gut p $75^{+}$cells, no difference was observed in the number of cells per neuron-only colony. f, Bmi-1 ${ }^{-1-}$ neural progenitor colonies in the absence of $\mathrm{Nrg}$ proliferated at a significantly lower rate than did wild-type colonies $\left({ }^{\star} P<0.01\right)$, but $B \mathrm{mi}^{-1} 1^{-1-}$ colonies in the presence of Nrg proliferated similarly to wildtype colonies (although the difference was still statistically significant, ${ }^{*} P<0.05$ ). 
expressed in the telencephalon (Supplementary Table 1). To identify additional pathways that are regulated directly or indirectly by $B m i-1$, we compared the gene expression profiles of wild-type and $B m i-1^{-1-}$ neurospheres that had been cultured from the P0 SVZ or from the P0 gut. Because Bmi-1 is a repressor ${ }^{21,22}$, and the function of Bmi-1 seems to be conserved between CNS and PNS stem cells, we examined whether any genes were significantly upregulated (fold change $>2 ; P<0.05)$ in $B m i-1^{-l-}$ neurospheres from both the CNS and PNS. We found 11 genes that met these criteria and that were confirmed to be expressed differentially in independent samples by qRT-PCR (out of 36,701 probe sets examined; Supplementary Table 2). In addition to $p 16^{\text {Ink4a }}$ and $p 19^{\text {Arf }}$, these included genes that were previously identified as being regulated by Bmi-1, such as Hox genes (hoxD8, hoxD9 and hoxC9 $)^{7,23,24}$, and several genes that have not been previously identified as being regulated by Bmi-1, such as the cyclin-dependent kinase inhibitor gene $p 21$, which regulates haematopoietic stem cell self-renewal ${ }^{25}$, and Gas6, which encodes a ligand for the Axl receptor tyrosine kinase $^{26}$. More work will be required to determine whether any of these genes regulate neural stem cell self-renewal.

Although Bmi-1 was found to be consistently required for the self-renewal of haematopoietic stem cells $s^{6,7}$, CNS stem cells and NCSCs, it was not required for the proliferation of restricted neuronal and glial progenitors from the forebrain or from the enteric nervous system (Fig. 4). It is not the case that all restricted progenitors proliferate normally in the absence of Bmi-1, because $B m i-1^{-1-}$ lymphocytes are also impaired in their proliferation ${ }^{3}$. It is also possible that other types of restricted neural progenitor (such as from other regions of the nervous system) might require Bmi-1 for proliferation as the intrinsic properties of neural progenitors vary among regions of the nervous system ${ }^{9}$. Nonetheless, Bmi-1 dependence distinguishes stem cell self-renewal from the proliferation of at least some types of restricted progenitor, providing insight that will help to elucidate these pathways further.

\section{Methods}

\section{Isolation of CNS and PNS progenitors}

Bmi-1 ${ }^{+1-}$ mice that had been backcrossed at least six times onto a C57BL/ 6 background were mated to generate E14.5 embryos, P0 pups, or 4-5-week-old adults that were genotyped by PCR (see Supplementary Information). $p 16^{-1-}$ mice were on an FVB background and were also genotyped by PCR. For CNS preparations, we dissected embryonic telencephalons or P0 or P30 SVZs as described ${ }^{16,27}$. CNS progenitors were dissociated and plated as described in the Supplementary Information. We processed embryonic gut tissues as described ${ }^{9}$. Dissociated embryonic gut cells were stained with an antibody against p75 (Chemicon International), and p75 ${ }^{+}$cells (which include NCSCs) were sorted by a FACSVantage dual-laser flow cytometer (Becton-Dickinson) into culture plates. Guts from P0 and P30 mice were dissected in ice-cold PBS, and the outer muscle/ plexus layers were peeled free from the underlying epithelium as described $^{2}$, dissociated and plated by pipette.

\section{Cell culture}

Cell suspensions were plated on adherent plates at clonal density, which means that cells were plated at a low density such that individual cells could form spatially distinct colonies $^{19}$. This allowed us to infer the developmental and proliferative potential of single cells on the basis of the types and numbers of cells that comprised each colony. For proliferation studies, $10 \mu \mathrm{M}$ BrdU was added to the cultures for $1 \mathrm{~h}$ at $37^{\circ} \mathrm{C}$ before the cells were fixed and stained with an antibody against BrdU. Culture conditions are described in the Supplementary Information.

For the neurosphere formation assays (non-adherent cultures) we used ultra-low binding plates (Corning). To test the self-renewal capacity of the neurospheres, individual CNS neurospheres were selected, centrifuged at $210 \mathrm{~g}$ for $4 \mathrm{~min}$, and then mechanically dissociated and replated. PNS neurospheres were plated for $24 \mathrm{~h}$ into plates treated with poly-D-lysine, and then trypsin-digested, mechanically dissociated, and replated. We quantified self-renewal as the number of secondary neurospheres generated per primary neurosphere $\left(2^{\circ} \mathrm{NS} / 1^{\circ} \mathrm{NS}\right)$.

\section{Tissue fixation and immunohistochemistry}

Mice were injected intraperitoneally with $50 \mathrm{mg}$ per $\mathrm{kg}$ (body weight) BrdU and killed after $2 \mathrm{~h}$ for perinatal mice and after $3 \mathrm{~h}$ for adult mice. The brains were fixed immediately in $4 \%$ paraformaldehyde and immunostained as described in the Supplementary Information

The methods used for qRT-PCR, western blot analysis and microarray analysis are described in the Supplementary Information.
Received 28 March; accepted 1 September 2003; doi:10.1038/nature02060. Published online 22 October 2003.

1. Morshead, C. M., Craig, C. G. \& van der Kooy, D. In vivo clonal analyses reveal the properties of endogenous neural stem cell proliferation in the adult mammalian forebrain. Development 125, 2251-2261 (1998).

2. Kruger, G. M. et al. Neural crest stem cells persist in the adult gut but undergo perinatal changes in self-renewal, neuronal subtype potential, and factor responsiveness. Neuron 35, 657-669 (2002)

3. van der Lugt, N. M. T. et al. Posterior transformation, neurological abnormalities, and severe hematopoietic defects in mice with a targeted deletion of the bmi-1 proto-oncogene. Genes Dev. 8, 757-769 (1994).

4. Haupt, Y., Bath, M. L., Harris, A. W. \& Adams, J. M. BMI-1 transgene induces lymphomas and collaborates with Myc in tumorigenesis. Oncogene 8, 3161-3164 (1993).

5. Alkema, M. J., Jacobs, H., van Lohuizen, M. \& Berns, A. Perturbation of B and T cell development and predisposition to lymphomagenesis in Eu-Bmil transgenic mice require the Bmil RING finger. Oncogene 15, 899-910 (1997).

6. Lessard, J. \& Sauvageau, G. Bmi-1 determines the proliferative capacity of normal and leukemic stem cells. Nature 423, 255-260 (2003).

7. Park, I.-K. et al. Bmi-1 is required for the maintenance of adult self-renewing hematopoietic stem cells. Nature 423, 302-305 (2003).

8. Davis, A. \& Temple, S. A self-renewing multipotential stem cell in embryonic rat cerebral cortex. Nature 372, 263-266 (1994).

9. Bixby, S., Kruger, G. M., Mosher, J. T., Joseph, N. M. \& Morrison, S. J. Cell-intrinsic differences between neural stem cells from different regions of the peripheral nervous system regulate the generation of neural diversity. Neuron 35, 643-656 (2002).

10. Jacobs, J. J. L., Kieboom, K., Marino, S., DePinho, R. A. \& van Lohuizen, M. The oncogene and polycomb-group gene bmi-1 regulates cell proliferation and senescence through the ink $4 a$ locus. Nature 397, 164-168 (1999).

11. Itahana, K. et al. Control of the replicative life span of human fibroblasts by p16 and the polycomb protein Bmi-1. Mol. Cell. Biol. 23, 389-401 (2003).

12. Jacobs, J. J. L. et al. Senescence bypass screen identifies TBX2, which represses Cdkn2a (p19ARF) and is amplified in a subset of human breast cancers. Nature Genet. 26, 291-298 (2000).

13. Sharpless, N. E. et al. Loss of $\mathrm{p} 16^{\text {Ink4a }}$ with retention of $\mathrm{p} 19^{\text {Arf }}$ predisposes mice to tumorigenesis. Nature 413, 86-91 (2001).

14. Lowe, S. W. \& Sherr, C. J. Tumor suppression by Ink4a-Arf: progress and puzzles. Curr. Opin. Genet. Dev. 13, 77-83 (2003).

15. Zindy, F., Quelle, D. E., Roussel, M. F. \& Sherr, C. J. Expression of the $\mathrm{p} 16^{\mathrm{INK} 4 \mathrm{a}}$ tumor suppressor versus other INK4 family members during mouse development and aging. Oncogene 15, 203-211 (1997).

16. Rietze, R. L. et al. Purification of a pluripotent neural stem cell from the adult mouse brain. Nature 412, 736-739 (2001).

17. Capela, A. \& Temple, S. LeX/ssea- 1 is expressed by adult mouse CNS stem cells, identifying them as nonependymal. Neuron 35, 865-875 (2002).

18. Shah, N. M., Groves, A. \& Anderson, D. J. Alternative neural crest cell fates are instructively promoted by TGF $\beta$ superfamily members. Cell $\mathbf{8 5}, 331-343$ (1996).

19. Morrison, S. J., White, P. M., Zock, C. \& Anderson, D. J. Prospective identification, isolation by flow cytometry, and in vivo self-renewal of multipotent mammalian neural crest stem cells. Cell 96, 737-749 (1999).

20. Shah, N. M., Marchionni, M. A., Isaacs, I., Stroobant, P. W. \& Anderson, D. J. Glial growth factor restricts mammalian neural crest stem cells to a glial fate. Cell 77, 349-360 (1994).

21. Bunker, C. A. \& Kingston, R. E. Transcriptional repression by Drosophila and mammalian polycomb group proteins in transfected mammalian cells. Mol. Cell. Biol. 14, 1721-1732 (1994).

22. Jacobs, J. J. L. \& van Lohuizen, M. Polycomb repression: from cellular memory to cellular proliferation and cancer. Biochim. Biophys. Acta 1602, 151-161 (2002).

23. Alkema, M. J., van der Lugt, N. M. T., Bobeldijk, R. C., Berns, A. \& van Lohuizen, M. Transformation of axial skeleton due to overexpression of bmi-1 in transgenic mice. Nature 374, 724-727 (1995).

24. van der Lugt, N. M. T., Alkema, M. J., Berns, A. \& Deschamps, J. The Polycomb-group homolog Bmi-1 is a regulator of murine Hox gene expression. Mech. Dev. 58, 153-164 (1996).

25. Cheng, T. et al. Hematopoietic stem cell quiescence maintained by p $21^{\text {cip } 1 / \text { wafl }}$. Science 287, 1804-1808 (2000)

26. Stritt, T. N. et al. The anticoagulation factor protein $\mathrm{S}$ and its relative Gas6, are ligands for the Tyro3/ Axl family of receptor tyrosine kinases. Cell 80, 661-670 (1995)

27. Lois, C. \& Alvarez-Buylla, A. Proliferating subventricular zone cells in the adult mammalian forebrain can differentiate into neurons and glia. Proc. Natl Acad. Sci. USA 90, 2074-2077 (1993).

Supplementary Information accompanies the paper on www.nature.com/nature.

Acknowledgements We thank M. Kukuruga, A. M. Deslaurier, M. Kiel and the University of Michigan Flow-Cytometry Core Facility (supported by University of Michigan Comprehensive Cancer and Multipurpose Arthritis Center NIH grants); D. Qian for mouse breeding; D. Misek, R. Koenig and R. Kuick for microarray analysis; E. Smith in the Hybridoma Core Facility (supported through the Michigan Diabetes Research and Training Center, and the Rheumatic Disease Center); M. van Lohuizen for the $\mathrm{Bmil}^{-1-}$ mice; and R. DePinho and D. Scadden for the $p 16^{-1-}$ mice. This work was supported by the NIH, the Searle Scholars Program and the Howard Hughes Medical Institute. A.V.M. was supported by a University of Michigan MSTP training grant. R.P. was the recipient of a postdoctoral fellowship from the Spanish Ministry of Science and Technology.

Competing interests statement The authors declare that they have no competing financial interests.

Correspondence and requests for materials should be addressed to S.J.M. (seanjm@umich.edu). The microarray data entitled "Neurospheres of WT and BMI-1 KO" has been deposited in the GEO (Gene Expression Omnibus) database under accession number GSE611. 